\title{
EFFECT OF DOPANT AND HEAT TREATMENT ON THE MICROSTRUCTURE AND MECHANICAL PROPERTIES OF NICKEL-ALUMINUM BRONZE
}

\author{
Franklin Amaechi Anene, Nkem Emelike Nwankwo, Victor Ugochukwu Nwoke \\ Metallurgical and Materials Engineering Department, Nnamdi Azikiwe University, \\ Awka, Anambra State, Nigeria
}

Received 10.05.2019

Accepted 13.06.2019

\begin{abstract}
The effect of dopant and heat treatment on the microstructure and mechanical properties of Nickel-aluminum bronze (Cu-10\%Al-5\%Ni-5\%Fe-x\%Mo) were extensively investigated. The cast samples were heat treated through different processes, including solutionizing, quenching, and aging; their microstructures were examined using an optical microscope, scanning electron microscopy and energy dispersive spectroscopy analysis and their mechanical properties determined. The microstructure of the as-cast samples consisted of $\mathrm{Cu}$-rich ' $\alpha$-phase, ' $\kappa$-phases and small volume fraction of $\beta$ '-phase while solutionizing transformed the $\beta$ '-phase to a homogenous $\beta$-phase, $\alpha$, and $\kappa$ phases. Quenching transformed all $\beta$ phase to $\beta^{\prime}$-phase, however, aging the alloy precipitated fine dispersive strengthening $\kappa$-phases from the quenched microstructure. The results of the mechanical tests showed that the aged samples had improved excellent mechanical properties compared to the as-cast samples. Compared to the base alloy, the tensile strength and hardness of the aged 2\% Mo sample increased by $58 \%$ and $55 \%$, respectively while the impact strength and elongation decreased by $27 \%$ and $22 \%$, respectively. Similarly, the tensile strength and hardness of the aged 3\% Mo sample increased by $44 \%$ and $49 \%$, respectively, while the impact strength and \% elongation decreased by $23.9 \%$ and $24.9 \%$, respectively.
\end{abstract} aging.

Keywords: NiAl bronze; dopant, heat treatment; microstructure; quenching;

\section{Introduction}

As-cast nickel-aluminum bronze (NAB), UNS C98500 (Cu-10Al-5Fe-5Ni), is an essential marine propeller material alloy extensively utilized due to its ability to retain its

*Corresponding author: Franklin Amaechi Anene, fa.anene@unizik.edu.ng 
original smooth machined surface over a long period and high notch resistance, as well as resistance to failure under impact when notched [1,2]. It is the advantage of a combination of high mechanical properties and superior corrosion resistance in seawater over other engineering materials is often exploited in marine industries [3], as well as broadly used as engineering parts, such as various worm-gears, gears, bearing, dies and valves $[4,5]$.

Studies have shown that nickel-aluminum bronze has a microstructure consisting of $\alpha$ (FCC Cu-rich solid solution), intermetallic precipitates with different morphologies ( $\kappa$ phases), and some $\beta^{\prime}$ phase $[6,7]$. Moreover, Wu et al. [8] found that quenching causes all $\beta$ phase transformed to $\beta^{\prime}$ phase while normalizing caused $\beta$ phase transformed to $\beta^{\prime}$, $\alpha$ and $\kappa$ phases, however, aging precipitates fine $\kappa$ phase from the as-quenched microstructure of $\beta^{\prime}$ phase and annealing causes the transformation of $\beta^{\prime}$ into $\alpha$ and $\kappa$ phases.

In the study of the solidification process of aluminum bronzes [9-13], the researchers reported that the BCC $\beta$ phase transforms to the FCC primary $\alpha$ phase with a Widmanstätten morphology and $\gamma_{2}$ (eutectoid reaction) while Jahanafrooz et al. [14] stated that $\mathrm{Fe}_{3} \mathrm{Al}$ particles are formed in $\beta$ phase and then they precipitate in $\alpha$ phase during cooling. Fuller et al. [15] investigated the effect of fusion welding and friction stir processing on the microstructural and mechanical properties of cast NiAl bronze. They published that different morphologies of $\kappa$ phase (such as globular and lamellar) could also form in $\alpha$ and $\beta$ phases at $800-900{ }^{\circ} \mathrm{C}$; whereas [16] established that the addition of Fe increases the percentage of $\alpha$ phase within the microstructure of aluminum-bronze, promotes the formation of $\kappa$ precipitates and reduces the amount of brittle $\gamma_{2}$ phase. Furthermore, increasing the Ni content of bronze decreases the percentage of $\beta$ and $\gamma_{2}$ phases and aids the formation of $\kappa$ phase [17]. Studies on the roles of the major alloying elements in NAB [18] showed that the existence of Fe in the composition of bronze improved wear resistance and fatigue strength. Meigh [19] posited that Al improves the casting and hot working characteristics, as well as the strength, iron aids in grain refinement and improves the tensile strength while $\mathrm{Ni}$ increases the corrosion resistance, yield strength and microstructural stabilization of nickel-aluminum bronze. Reports in literature [20] demonstrated that heat treatment affects remarkably the microstructure of $\mathrm{NAB}$ and its mechanical properties. The strength and hardness increase with the increasing content of hard phases in the alloy while quenching, normalizing and aging improved the tensile strength and hardness with a corresponding fall in elongation. Friction-stir processing (FSP) method was adopted to modify the microstructure of ascast nickel-aluminum bronze [21, 22], it was observed that the initial coarse microstructure of the cast NAB was transformed to a fine structure, the porosity defects were eliminated, with an increased surface hardness and lower wear rate. Furthermore, in the study of the microstructure and mechanical properties of peened nickel aluminum bronze [23] posited that shot peening improved the hardness and compressive residual stress of the surface layer of NAB.

Given the ever-increasing demand and usage of NAB components, it becomes apparent to improve their service life by enhancing their mechanical properties such as tensile strength, fracture toughness, ductility, hardness, high resistance to general corrosion. Although several researchers have focused on the heat treatment and microstructural evolution of NAB components, the effect of Molybdenum in NAB and heat treatment have not been exhaustively investigated. Thus, this study intends to explore 
the effect of the dopant and heat treatment on the microstructure and mechanical properties of NAB.

\section{Methodology}

\section{Specimen preparation}

The die casting method was adopted for this research, bailout graphite crucible furnace with a crucible pot placed at the center of the furnace was used for the melting. A compact electronic scale was used to weigh the calculated wt.\% of copper scrap which was preheated preparatory to charging it into the furnace and then heated to about 1083 ${ }^{\circ} \mathrm{C}$ when the aluminum scrap was charged and stirred. The calculated wt.\% of trace additives $\mathrm{Ni}, \mathrm{Fe}$, and Mo pellets were wrapped in aluminum foil and inserted into the melt. As melting progressed, the melt was stirred intermittently to promote a homogenous melt throughout the experiment. After melting, the crucible pot was removed with a pair of tongs and casting into the preheated steel molds was steadily and the liquid alloy was allowed to solidify and cool in the mold. The developed alloy in the as-cast state was subjected to different heat treatments. The specimens were solution treated at $900{ }^{\circ} \mathrm{C}$ for 2 hours, air quenched, and water quenched. The water quenched samples were aged at $600{ }^{\circ} \mathrm{C}$ for 3 hours and air cool.

\section{Optical micrograph, SEMs, and EDS Analysis}

The microstructural evaluation of the morphologies of the developed alloys (ascast and heat-treated specimens) were done using a metallurgical optical microscope and scanning electron microscope (SEM) with energy dispersive spectroscopy (EDS). The specimens were prepared by grinding using a fairly coarse file and series of emery paper of grits sizes ranging from 400 to $1200 \mu \mathrm{m}$, polishing and etching with a solution of $5 \mathrm{~g}$ $\mathrm{FeCl}_{3}, 5 \mathrm{ml} \mathrm{HCl}$ and $100 \mathrm{ml} \mathrm{H} 2 \mathrm{O}$.

\section{Mechanical tests}

Mechanical testing is to determine the properties or the mechanical states of a material that are associated with elastic and inelastic reactions to force or that involve relationships between stress and strain (ASTM E28.91). The mechanical properties such as ultimate tensile strength, Brinell hardness, impact strength, and elongation were tested with 100JPL tensile strength tester, high precision reading Brinell hardness tester and impact testing machine, respectively. The tensile strength is the maximum tensile stress the specimens were capable of sustaining to fracture. In the Brinell hardness test, a tungsten carbide ball indenter was forced into the specimens for 15 seconds, and the diameter of the indentation left in the surface after removal of the test force measured. For the impact test, the energy absorbed after the pendulum broke the specimens, was measured as the difference between the height of drop before fracture and the height of rising after a fracture. The dimension of the tensile strength specimen was $150 \mathrm{~mm}$ overall length, and $20 \mathrm{~mm}$ end section diameter with gauge length and diameter of $50 \mathrm{~mm}$ and $10 \mathrm{~mm}$ respectively according to [ASTM E8/E 8M] and that of the impact toughness specimen was $10 \times 10 \times 55 \mathrm{~mm}$ with a $2 \mathrm{~mm}\left(\Delta 45^{\circ}\right)$ deep notch at the center in line with standard [ASTM E23-07 $\mathrm{a}^{\varepsilon 1}$ ] whereas the Brinell hardness test specimen was $20 \times 20 \mathrm{~mm}$ as stated in standard [ASTM E10-08]. Three specimens were tested for each experiment and the average taken as the result. 


\section{Results and Discussion}

\section{Microstructures}

Under equilibrium conditions, the microstructure of $\mathrm{Cu}-10 \mathrm{Al}-5 \mathrm{Ni}-5 \mathrm{Fe}$ comprises of columnar grains of copper-rich solid solution known as $\alpha$-phase and a small volume fraction of $\beta$-phase or retained martensitic $\beta^{\prime}$-phase, surrounded by four different types of Fe-rich intermetallic $\kappa$-phases. Among these intermetallic phases, $\kappa_{\mathrm{I}}$-phase is rosette shaped precipitate ranging from $5-10 \mu \mathrm{m}$ in diameter, $\kappa_{\mathrm{II}}$-phase is similar (ranging from 1-2 $\mu \mathrm{m}$ in diameter) dendritic rosette shaped phase distributed mostly at the $\alpha / \beta$ boundaries. $\kappa_{\mathrm{III}}$-phase is a fine lamellar "finger-like" eutectoid structure, while the $\kappa_{\mathrm{IV}}$ phase is a fine precipitate with highest Fe-content among the intermetallics that are of varying sizes $(<0.5 \mu \mathrm{m}$ in diameter) with plate-like morphology and is distributed uniformly within the $\alpha$-matrix [1, 23-27]. The optical micrographs and SEMs of the ascast specimens (NiAl bronze with $2 \%$ Mo and $3 \%$ Mo contents) tested in this study are shown in Fig. 1(a-f). The microstructure of the NiAl bronze consists of large grains of coarse $\mathrm{Cu}$-rich $\alpha$-phase with interspersed $\kappa$-phases within the $\beta^{\prime}$ matrix while the microstructures of the as-cast NAB with $2 \% \mathrm{Mo}$ and $3 \% \mathrm{Mo}$ contents revealed phases similar to that of as-cast NAB with large grains of coarse $\mathrm{Cu}$-rich $\alpha$-phase, limited $\beta^{\prime}$ phase, and interspersed $\kappa$-phases.
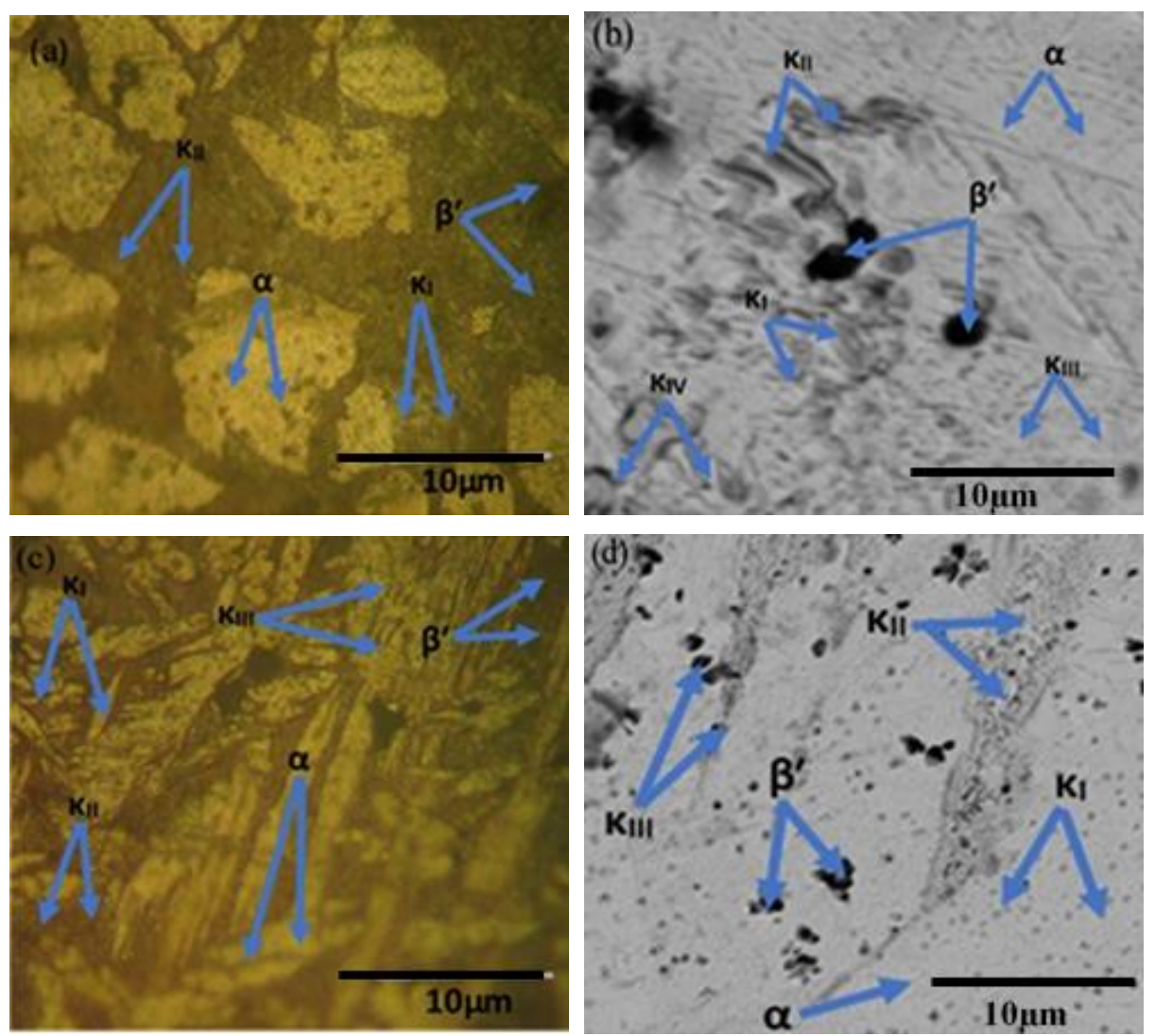

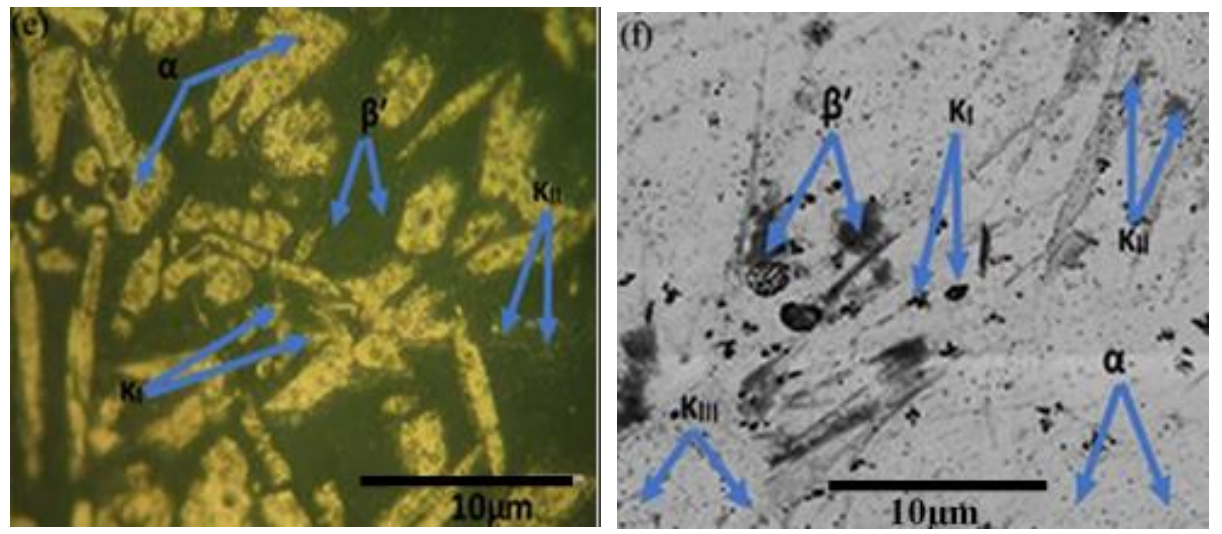

Fig. 1. As-cast specimens (a) and (b) optical micrograph and SEM of NiAl bronze, $(c)$ and $(d)$ optical micrograph and SEM of NiAl bronze with $2 \% \mathrm{Mo},(e)$ and $(f)$ optical micrograph and SEM of NiAl bronze with $3 \%$ Mo.

Also, the optical micrographs and SEMs of the air quenched and water quenched specimens are shown in Fig. 2(a-e). The microstructure of the air quenched specimens mainly contains fine $\beta$-phase evenly dispersed within the $\alpha$-matrix and small precipitates of $\kappa$-phases. The microstructure of the water quenched specimens consists more of the martensitic supersaturated solid solution $\beta^{\prime}$-phase with precipitated $\kappa$-phases dispersed within the small volume fraction of $\alpha$-matrix as represented accordingly in the figure. Furthermore, shown in Fig 2(f-h) are the optical micrographs and SEMs of the aged specimens. Evenly dispersed fine $\kappa$-phases was observed in the aged specimens where the solute atoms such as $\mathrm{Al}, \mathrm{Fe}, \mathrm{Ni}$ and Mo cluster and dissociate out from the quenched matrix to precipitate the dispersive strengthening $\kappa$-phases. The aged $2 \%$ Mo alloy has more $\mathrm{Cu}$-rich $\alpha$-phase and less $\beta$-phase than the aged 3\% Mo alloy.
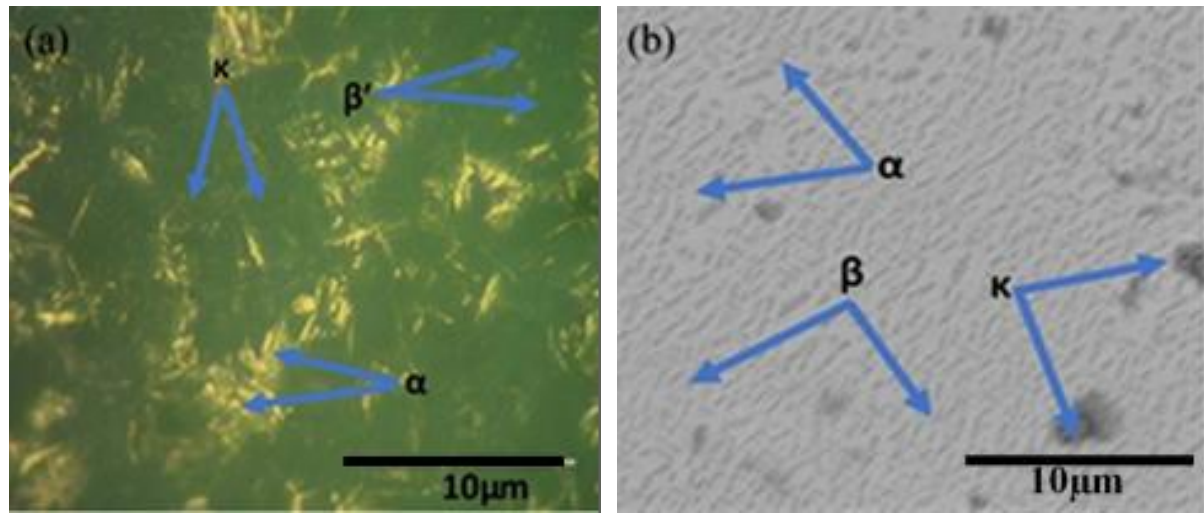

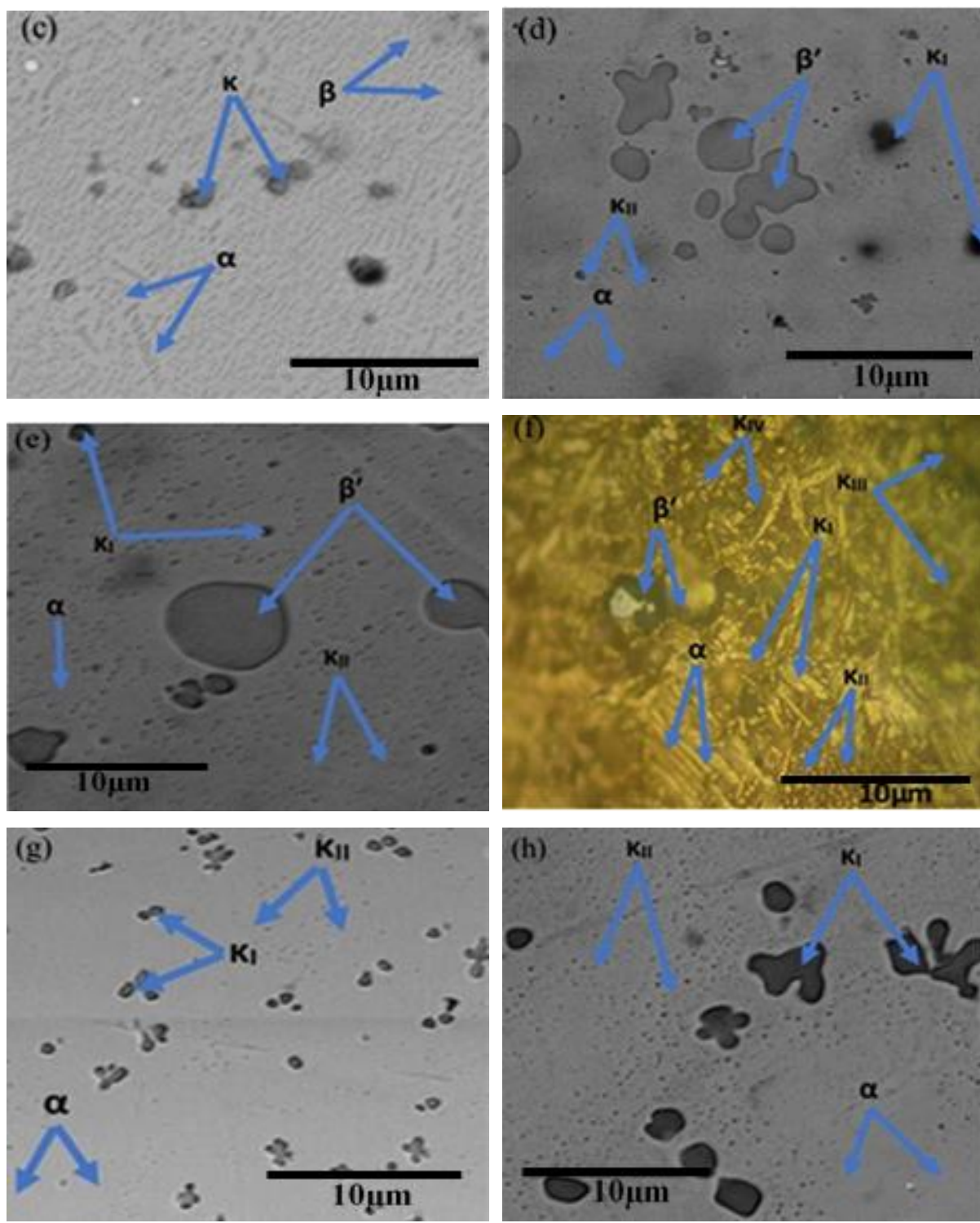

Fig. 2. Optical micrographs and SEMs of NiAl bronze: (a) water quenched, 3\% Mo, (b) air quenched, $2 \% \mathrm{Mo},(c)$ air quenched, $3 \% \mathrm{Mo},(d)$ water quenched, $2 \% \mathrm{Mo}$, (e) water quenched, 3\% Mo, (f) aged, 2\% Mo, ( $g$ ) aged, 2\% Mo, (h) aged, 3\% Mo.

Energy Dispersive Spectroscopy (EDS) Analysis

Fig. 3, shows the EDS analysis of the as-cast 3\% Mo alloy with two observed spectra in the microstructure namely: spectrum 7 which contains $\mathrm{O}, \mathrm{Fe}, \mathrm{S}, \mathrm{Cu}, \mathrm{Ni}$ and $\mathrm{Al}$ elements and spectrum 8 with $\mathrm{Cu}, \mathrm{C}, \mathrm{Al}, \mathrm{Ni}, \mathrm{Fe}$, and $\mathrm{O}$ elements respectively in descending order of wt. $\%$. 

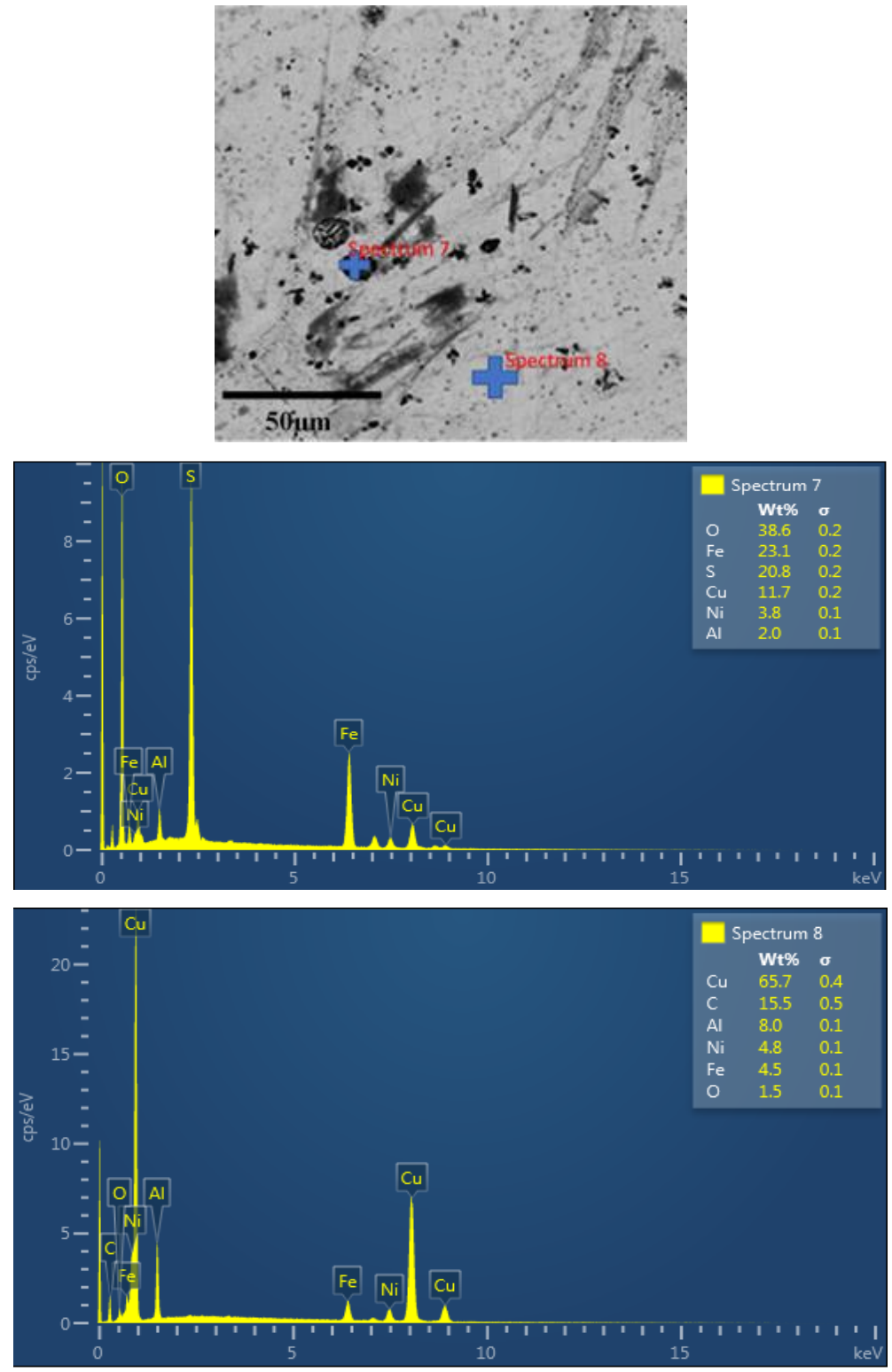

Fig. 3. NiAl bronze, EDS analysis of spectra (7 and 8) of the as-cast specimen.

The EDS analysis of the air quenched specimen is shown in Fig. 4. From the figure, two major phases in the microstructure were distinguished as spectrum 9 with elements $\mathrm{Cu}, \mathrm{C}, \mathrm{Zr}, \mathrm{Al}, \mathrm{Fe}, \mathrm{O}$ and $\mathrm{Ni}$ and spectrum 10 consisting of $\mathrm{Cu}, \mathrm{Al}, \mathrm{Fe}, \mathrm{C}$, and $\mathrm{Ni}$ elements respectively in descending order of wt.\%. 

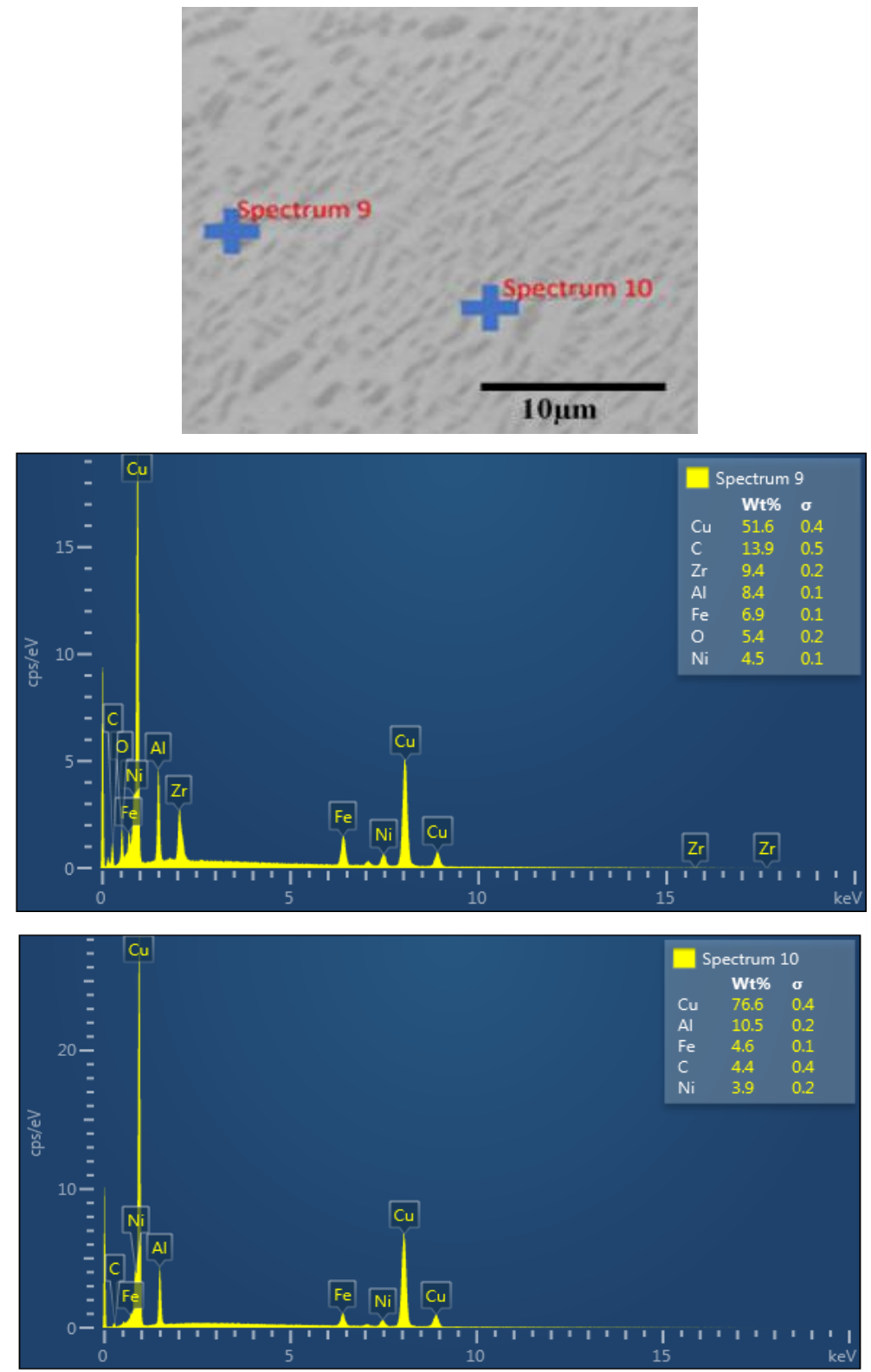

Fig. 4. NiAl bronze, EDS analysis of spectra (9 and 10) of the air-quenched specimen.

Also, Fig. 5 presents the EDS analysis of the water quenched specimen with the compositions of the elements in the two major phases (spectrum 5 and spectrum 6) observed in the microstructure. Spectrum 5 consists of $\mathrm{Fe}, \mathrm{C}, \mathrm{Cu}, \mathrm{Al}, \mathrm{Mo}, \mathrm{O}, \mathrm{F}$, and $\mathrm{Si}$ while spectrum 6 comprises of $\mathrm{Cu}, \mathrm{C}, \mathrm{Al}, \mathrm{Fe}$, and $\mathrm{O}$ respectively in descending order of wt.\%. 

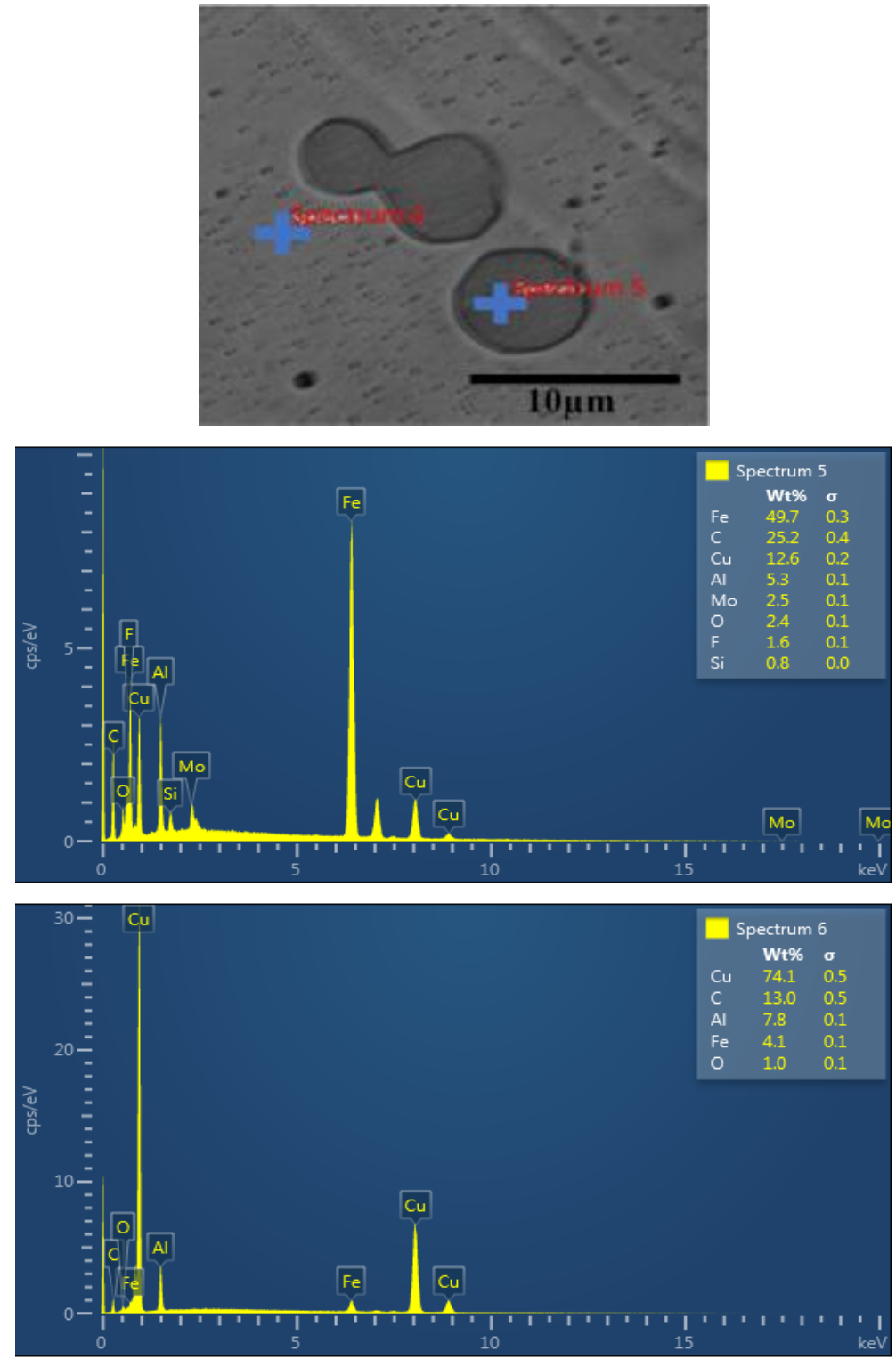

Fig. 5. NiAl bronze, EDS analysis of spectra (5 and 6) of water quenched specimen.

Lastly, EDS analysis of the aged specimens is shown in Fig. $6(a, b)$. The EDS categorized two phases in the microstructure as spectrum 1 and spectrum 2 for the aged $2 \%$ Mo alloy with the composition of spectrum one as $\mathrm{Cu}, \mathrm{Al}$, and $\mathrm{C}$ and spectrum two as $\mathrm{Cu}, \mathrm{C}, \mathrm{Al}$, and $\mathrm{O}$ respectively. Also, two crucial phases were distinguished as spectrum 3 and 4 in the microstructure of the aged $3 \%$ Mo alloy with spectrum 3 containing $\mathrm{Cu}, \mathrm{C}$, $\mathrm{O}, \mathrm{Al}, \mathrm{Ni}$ and $\mathrm{Fe}$ while spectrum 4 consists of $\mathrm{Cu}, \mathrm{C}, \mathrm{Al}, \mathrm{Fe}, \mathrm{Ni}$ and $\mathrm{O}$ elements respectively in descending order of wt. $\%$. 

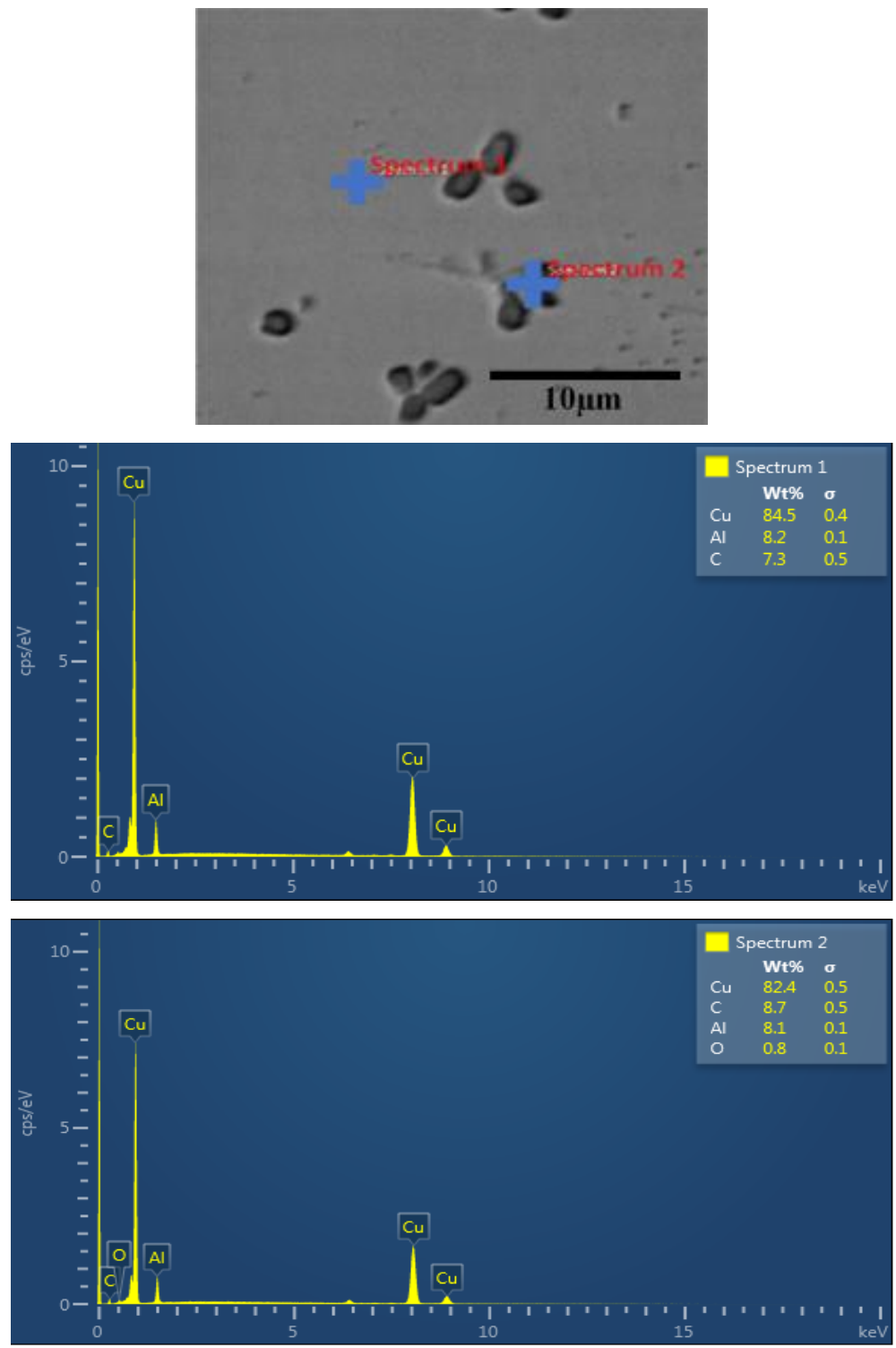

(a) 

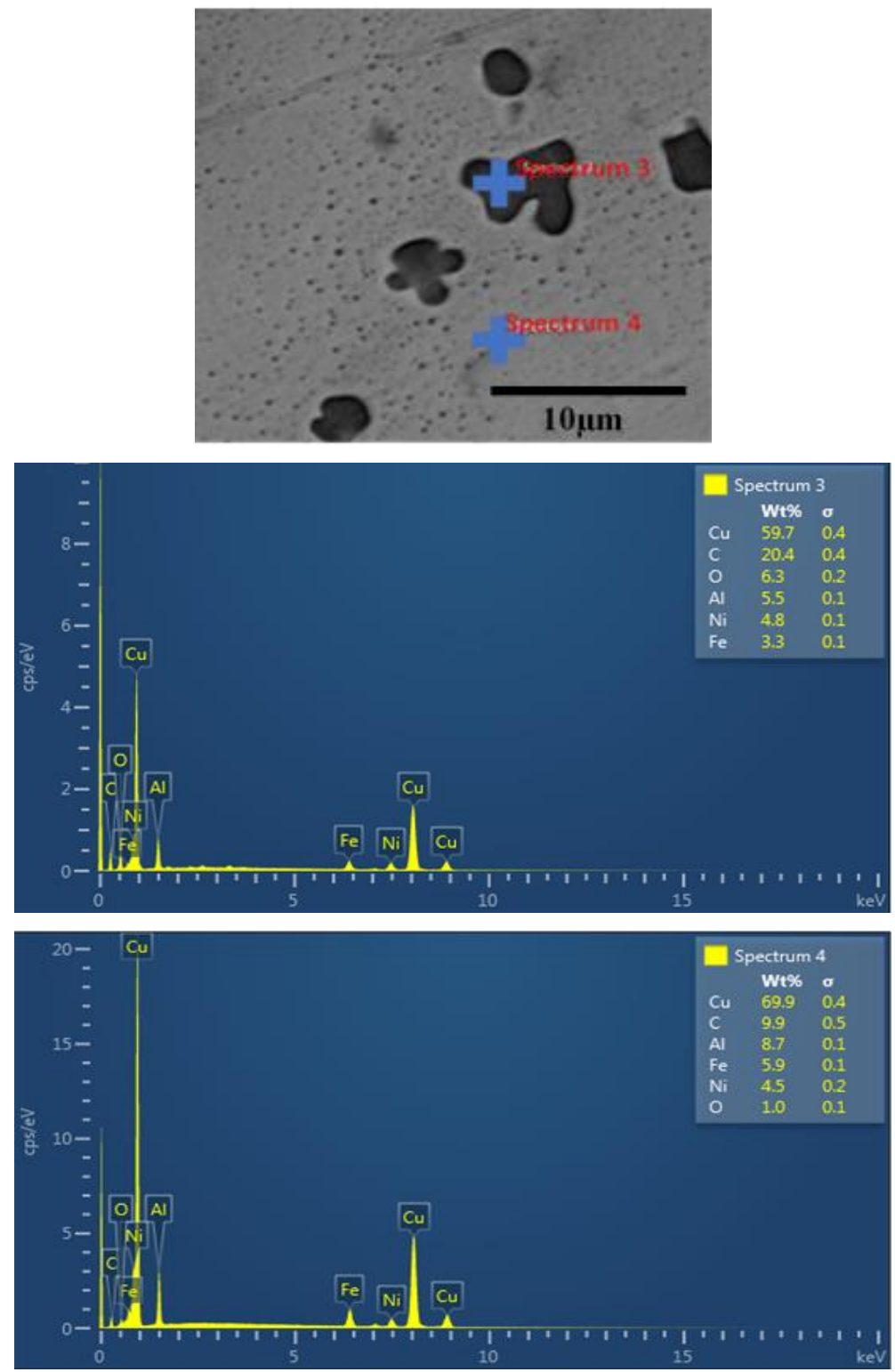

(b)

Fig. 6. NiAl bronze, (a): EDS analysis of spectra (1 and 2) of aged 2\% Mo specimen, and (b): EDS analysis of spectra (3 and 4) of aged 3\% Mo specimen. 


\section{Mechanical Properties}

The mechanical tests in this study include ultimate tensile strength (UTS), Brinell hardness, impact strength, and percentage elongation. Alloying and heat treatment affected the mechanical properties through the change in the morphology of their microstructures. The test conditions for Brinell hardness test in this research include HBW 5/750 Brinell hardness scale, $5 \mathrm{~mm}$ ball diameter, $7355 \mathrm{~N}$ or $750 \mathrm{kgf}$ nominal force with $15 \mathrm{~s}$ loading time [ASTM 10-08]. The mechanical property test results and their corresponding graphs are shown in Tab. 1 and Fig 7.

Table 1. Mechanical test results.

\begin{tabular}{|c|c|c|c|c|}
\hline Samples & UTS(MPa) & Hardness (HBW 5/750) & $\operatorname{Impact}(\mathrm{J})$ & $\% \mathrm{E}$ \\
\hline $\mathrm{ACB}$ & 434 & 291 & 68 & 34 \\
\hline $\mathrm{AC}_{1}$ & 457 & 328 & 56 & 32 \\
\hline $\mathrm{AC}_{2}$ & 460 & 355 & 54 & 31 \\
\hline $\mathrm{AQ}_{1}$ & 532 & 395 & 48 & 24 \\
\hline $\mathrm{AQ}_{2}$ & 667 & 410 & 44 & 25 \\
\hline $\mathrm{WQ}_{1}$ & 701 & 462 & 31 & 20 \\
\hline $\mathrm{WQ}_{2}$ & 712 & 475 & 28 & 19 \\
\hline $\mathrm{A}_{1}$ & 686 & 419 & 49 & 26 \\
\hline $\mathrm{A}_{2}$ & 675 & 435 & 53 & 26 \\
\hline
\end{tabular}

*ACB: As-cast NiAl bronze, ACl: As-cast 2\% Mo, AC 2 : As-cast 3\% Mo, AQ $Q_{1}$ : Air quenched $2 \%$ Mo, AQ $Q_{2}$ : Air quenched 3\% Mo, WQ $Q_{1}$ Quenched 2\% Mo, WQ $Q_{2}:$ Quenched 3\% Mo, Al: Aged 2\% Mo, A2: Aged $3 \%$ Mo. 
(a)

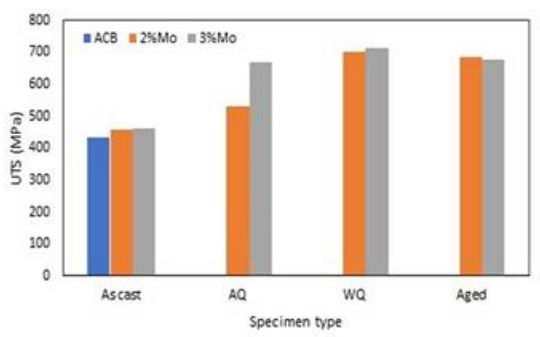

(c)

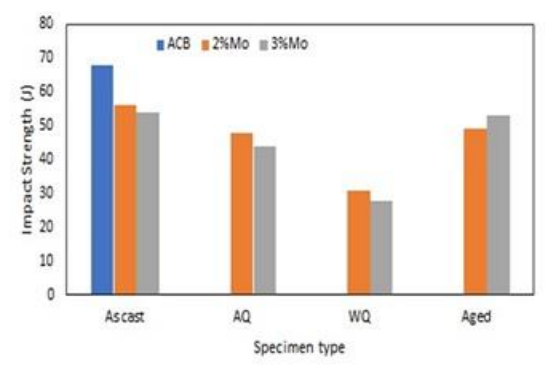

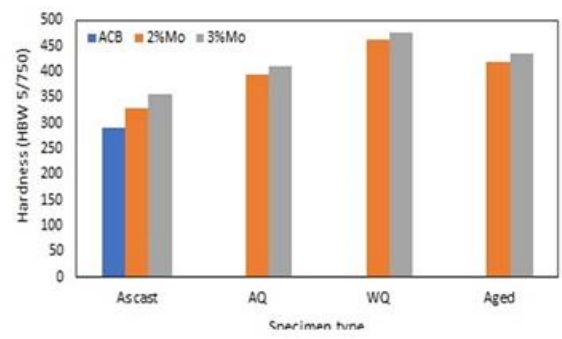

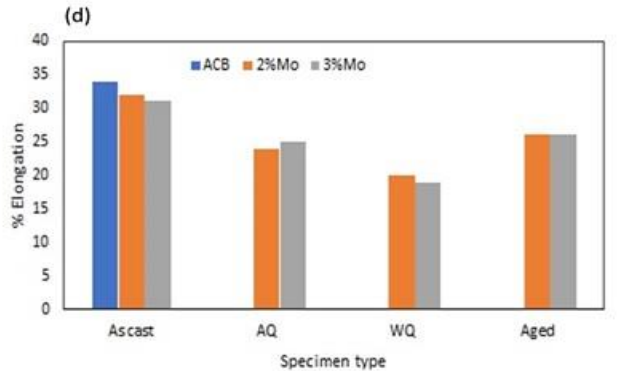

Fig. 7. Multiple bar charts: (a) ultimate tensile strength, (b) Brinell hardness, (c) impact strength, (d) elongation against specimen type.

The highest tensile strength and hardness values but with compromised impact strength and percentage elongation were observed in quenched specimens with $2 \%$ and $3 \%$ Mo contents containing a high percentage of $\beta^{\prime}$-phase in their microstructure. Moreover, the transformation of the $\beta^{\prime}$-phase to evenly distributed $\beta$-phase and finegrained $\kappa$-phases in the microstructure by aging treatment resulted in the best combination of improved mechanical properties in terms of all the tested mechanical properties. All the as-cast specimens: NAB, 2\% Mo and 3\% Mo contents had the highest impact strength and percentage elongation with moderate tensile strength and hardness values owing to the morphology of their microstructure which contains the $\alpha$-phase grains of copper-rich solid solution and small volume fraction of the $\beta^{\prime}$-phase and $\kappa$-phases. Furthermore, solutionizing and air quenching improved the mechanical properties compared to the ascast specimens, which could be related to the transformation of the $\alpha$-phase to $\beta$-phase with small amount $\kappa$-phases in the microstructure.

\section{Conclusion}

The effect of dopant and heat treatment on the microstructure and mechanical properties of nickel-aluminum bronze $(\mathrm{Cu}-10 \mathrm{Al}-5 \mathrm{Ni}-5 \mathrm{Fe}-\mathrm{xMo})$ were studied and the following deductions derived:

1. The microstructure of the as-cast (NAB, 2\% Mo and 3\% Mo contents) were mixtures of coarse $\alpha$-phase, the small volume fraction of $\beta^{\prime}$-phase and precipitates of $\kappa$-phases. Solutionizing at 900 for $2 \mathrm{hrs}$ and air quenching transformed the coarse $\alpha$-phase to $\beta$-phase while water quenching produced the martensitic $\beta^{\prime}$-phase. 
2. Aging heat treatment resulted in the precipitation and evenly distribution of finegrained $\kappa$-phases from the water quenched $\beta^{\prime}$ microstructure which led to the observed best combination of optimum mechanical properties.

3. Not only modifying the base alloy with Mo improved the mechanical properties of the as-cast NAB, but also the aging heat treatment further enhanced the mechanical properties. The aged $2 \%$ Mo alloy gave the highest ultimate tensile strength while the aged 3\% Mo has the highest hardness and impact strength values.

\section{Acknowledgment}

TETFUND sponsored this research work under batch $8^{\text {th }}$ of TETFUND 2014-2015

Research Projects intervention to Nnamdi Azikiwe University, Awka. (TETFUND/DESS/NAU/AWKA/RP/VOL.VIII).

\section{References}

[1] A. Al-Hashem, W Riad: Mater Charact, 48 (1), (2002) 37-41.

[2] Fu, Zhong-tao, Wen-yu Yang, Si-qi Zeng, Bu-peng Guo, and Shu-bing Hu: Trans Nonferrous Met Soc China, 26 (2016) 1105-1111.

[3] J.S. Carlton, Marine propellers and propulsion, second ed., Elsevier Ltd. USA, 2007, 382-393

[4] A. Tuthill, "Guidelines for the use of copper alloys in seawater." NiDI Publication 12003 (1988): 1-2.

https://www.copper.org/publications/pub_list/pdf/A7032-seawater-corrosion.pdf

[5] Li, Wen-sheng, Zhi-ping Wang, L. U. Yang, G. A. O. Yong, and Jian-lin Xu: Trans Nonferrous Met Soc China, 16 (2006) 607-612.

[6] F. Hasan, A. Jahanafrooz, G. W. Lorimer, and Ni Ridley: Metall Trans A, 13 (1982) 1337-1345.

[7] T. Küçükömeroğlu, E. Şentürk, L. Kara, G. İpekoğlu, and G. Çam: J Mater Eng Perform, 25 (2016): 320-326.

[8] Zhong Wu, Y. Frank Cheng, Lei Liu, Weijie Lv, and Wenbin Hu: Corros Sci, 98 (2015) 260-270.

[9] F. Hasan, A. Jahanafrooz, G. W. Lorimer, and Ni Ridley: Metall Trans A, 13 (1982) 1337-1345.

[10] E. A. Culpan, and G. Rose: Br Corros J, 14 (1979) 160-166.

[11] P Brezina: Int Met Rev, 27 (1982) 77-120.

[12] E. A. Culpan, and G. Rose: Journal of Materials Science 13 (1978) 1647-1657.

[13] F. Hasan, G. W. Lorimer, and N. Ridley: Le Journal de Physique Colloques, 43 (1982): C4-653.

[14] A. Jahanafrooz, F. Hasan, G. W. Lorimer, and N. Ridley: Metall Trans A, 14 (1983) 1951-1956.

[15] M. D. Fuller, S. Swaminathan, A. P. Zhilyaev, and T. R. McNelley: Mater Sci Eng: A, 463 (2007) 128-137.

[16] Rizi, Mostafa Saboktakin, and Amir Hossein Kokabi: J Mater Process Technol, 214 (2014) 1524-1529.

[17] J. Łabanowski, and Tomasz Olkowski: Advances in Materials Sciences, 9 (2009) 23-29.

[18] D. R. Ni, P. Xue, D. Wang, B. L. Xiao, and Z. Y. Ma: Mater Sci Eng: A, 524 (2009) 119-128. 
[19] H. Meigh, Cast and wrought aluminium bronzes properties, processes and structure. IOM Communications, London, 2000.

[20] Wu, Zhong, Y. Frank Cheng, Lei Liu, Weijie Lv, and Wenbin Hu: Corros. Sci, 98 (2015) 260-270.

[21] D. R. Ni, B. L. Xiao, Z. Y. Ma, Y. X. Qiao, and Y. G. Zheng: Corros Sci, 52 (2010) 1610-1617.

[22] Thapliyal, Shivraman, and Dheerendra Kumar Dwivedi: J Mater Process Technol, 238 (2016) 30-38.

[23] Chengxi Wang, Chuanhai Jiang, Ze Chai, Ming Chen, Lianbo Wang, and Vincent Ji: Surf Coat Technol, 313 (2017) 136-142.

[24] J. Basumatary, M. Nie, and R. J. K. Wood: Journal of Bio-and Tribo-Corrosion, 1 (2015) 12.

[25] R. J. K. Wood, and S. P. Hutton: Wear, 140 (1990) 387-394.

[26] J. Malik, I. H. Toor, W. H. Ahmed, Z. M. Gasem, M. A. Habib, R. Ben-Mansour, and H. M. Badr: Int J Electrochem Sci, 9 (2014) 6765-6780.

[27] S. Nesic, Daniel A. Gulino, and Ramakrishna Malka. "Erosion Corrosion and Synergistic Effects in Disturbed Liquid Particle Flow." In CORROSION 2006. NACE International, 2006, no.6594.

[28] Z. B. Zheng, and Y. G. Zheng: Corros Sci, 102 (2016) 259-268.

[29] ASTM (E28.91), ASTM International Technical Committee E28 on Mechanical Testing and subcommittee E28.91 on Terminology, Annual book of ASTM standards. (03.01), 2009.

[30] ASTM (E8/E 8M). Standard Test Methods for Testing of Metallic Materials. Annual Book of ASTM Standards. Section three, Metals Test Methods and Analytical procedures. (03.01), 2009.

[31] ASTM (E23-O7ac1). Standard Test Methods for Notched Bar Impact testing of Metallic Materials. Annual Book of ASTM Standards. Section three, Metals Test Methods and Analytical procedures. (03.01), 2009.

[32] ASTM (E10-08). Standard Test Method for Brinell Hardness of Metallic Materials. Annual Book of ASTM Standards. Section three, Metals Test Methods and Analytical procedures. (03.01), 2009.

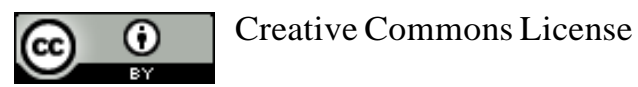

This work is licensed under a Creative Commons Attribution 4.0 International License. 